\title{
Trypanosoma cruzi Infection in Leontopithecus rosalia at the Reserva Biológica de Poço das Antas, Rio de Janeiro, Brazil
}

\author{
Cristiane V Lisboa, James Dietz**, Andrew J Baker***, Nédia N Russel*, \\ Ana M Jansen ${ }^{+}$
}

\begin{abstract}
Departamento de Protozoologia *Departamento de Bioquímica e Biologia Molecular, Instituto Oswaldo Cruz, Av. Brasil 4365, 21045-900 Rio de Janeiro, RJ, Brasil **Departament of Zoology, University of Maryland, USA ***Philadelphia Zoological Garden, Philadelphia, USA
\end{abstract}

Wild golden lion tamarins (Leontopithecus rosalia) - endangered primates that are native to the Brazilian Atlantic coastal forest - were surveyed for the presence of Trypanosoma cruzi with the use of Giemsa-stained blood smears, hemocultures and an indirect immunofluorescence assay (IFAT). Positive IFAT with titers ranging from 1:20 to 1:1280 were observed in 52\% of the 118 wild tamarins examined and the parasite was isolated from 38 tamarins. No patent parasitemia was observed among the tamarins from which T. cruzi was isolated. Serum conversion and positive hemoculture was observed for three animals that had yielded negative results some months earlier, which indicates that $\mathrm{T}$. cruzi is actively transmitted among tamarins. In contrast to observations with other sylvatic isolates, those from the tamarins were significantly more virulent and most of them produced mortality in experimentally infected Swiss mice. Some variation in the kDNA restriction profiles among the isolates was observed. Electrophoresis with GPI, G6PDH, IDH, MDH and ME enzymes showed a Z2 profile.

Key words: Trypanosoma cruzi - Leontopithecus rosalia - sylvatic cycle - electrophoresis profiles - Brazil

Trypanosoma cruzi, a kinetoplastid Tripanosomatidae, circulates among hundreds of mammalian species and dozens of triatomine bugs (Brener 1973). The parasite's life cycle comprises two multiplicative stages: intracellular amastigotes in the mammalian host and extracellular epimastigotes in the gut of triatomines or in the lumen of the scent glands of the opossum Didelphis marsupialis (Deane et al. 1984). T. cruzi is a very heterogeneous parasite species; it is composed of significantly different subpopulations with regard to biological, biochemical and molecular parameters. The attempts that have been made to establish correlation between these markers and any biological parameter have led to controversial results. However analysis of the electrophoretic profiles of isoenzymes has defined three zymodemes that correspond to the sylvatic transmission cycle (Z1 and Z3) and to the domestic transmission cycle (Z2). This characterization

Financial support: Papes/CNPq, Faperj/IOC, AMLD/ WWF, Ibama.

${ }^{+}$Corresponding author. Fax: +55-21-598.4325. E-mail: jansen@gene.dbbm.fiocruz

Received 9 July 1999

Accepted 20 March 2000 showed that the domiciliar transmission cycle of $T$. cruzi can be quite independent from the sylvatic transmission cycle although they sometimes overlap (Miles et al. 1977, Miles 1983, Miles \& Cibulskis 1986). The molecular markers (rRNA and mini-exon genes) have divided several T. cruzi isolates into two lineages that were also related to the domestic (lineage 1) and to the sylvatic transmission cycle (lineage 2) (Zingales et al. 1998). More recently, at an international meeting in Rio de Janeiro, Brazil, the main zymodemes and lineages were redefined as two groups termed $T$. cruzi II and $T$. cruzi I, corresponding $\mathrm{Z} 2$ to lineage 1 and $\mathrm{Z} 1$ to lineage 2 , respectively.

Natural infection by $T$. cruzi in non-human primates has been reported among Allouatta senicula, Cebus apella, C. capucinus (Marinkelle 1966); Saimiri boliviensis (Ayala 1961, Sullivan et al. 1993); S. sciureus (Aben-Athar 1922, Chagas 1924, Deane \& Damasceno 1961, Marinkelle 1966); Callithrix jacchus (Deane 1962); Chiropotes satanas, Pithecia pithecia, Callicebus torquatus (Deane et al. 1970); Lagothrix lagotricha, Ateles fusciceps, Cebuella pygmaea, Saguinus mystax and S. oedipus (Ayala et al. 1973, Marinkelle 1982). Although experimentally infected non-human primates develop an acute infection that is similar to acute Chagas disease, they do not develop a comparable chronic phase of the infection (Marsden et 
al. 1970, Rosner et al. 1988, Bonecini-Almeida et al. 1990, Almeida et al. 1992).

Golden lion tamarins (Callitrichidae: Leontopithecus rosalia) are endemic to the Atlantic Coastal Forest of Rio de Janeiro, Brazil. An international program to save golden lion tamarins was launched in 1983 at the Reserva Biológica de Poço das Antas, in the State of Rio de Janeiro. This reserve holds the largest wild population of golden lion tamarins: about 290 individuals distributed in approximately 45 territorial groups (Kleiman et al. 1990, Kierulff \& Oliveira 1994). One of the aims of this program is to reduce the probability of extinction of this species in the wild when reintroducing captive-born tamarins into the forest and when translocating wild-born tamarins.

In order to evaluate the eventual parasite dispersion as a consequence of this program, the prevalence and the dynamics of transmission of $T$. cruzi infection among golden lion tamarins was investigated, and the biological and biochemical characterization of the isolates was performed as well.

\section{MATERIALS AND METHODS}

The study area - The Reserva Biológica de Poço das Antas is located $70 \mathrm{~km}$ NE of Rio de Janeiro city, between $22^{\circ} 30^{\prime}$ and $22^{\circ} 33^{\prime}$ south latitude and $42^{\circ} 15^{\prime}$ and $42^{\circ} 19^{\prime}$ west longitude. The reserve has an area of 5,200 ha and is isolated from other forested lands along most of its perimeter. It is a patchwork of grasslands and forests in early to late secundary sucession that resulted from clear cutting and selective cutting prior to 1973. Climate on the reserve is seasonal, most of the rain is concentrated in the warmer months of October through March (Dietz et al. 1994).

Tamarins' capture - As part of an ongoing research, a total of 118 sylvatic tamarins in breeding groups and in all age classes were noninjuriously captured and anesthetized with $20 \mathrm{mg} / \mathrm{kg}$ body weight ketamine between October 1995 and October 1998 (Baker et al. 1993, Dietz et al. 1994). All studied animals were from the Reserva Biológica de Poço das Antas.

Hemocultures and serology - Approximately 0.1 $\mathrm{ml}$ of whole blood that was obtained by puncture of the femoral vein was placed in NNN medium (Novyl, McNeal and Nicolle), covered with an overlay of LIT (Liver Infusion Tryptose), mixed with $10 \%$ fetal calf serum and $140 \mathrm{mg} / \mathrm{ml}$ of gentamicin sulfate. The tubes were examined every 14 days over two months in cases where serological results were negative and for longer periods in cases where they were positive. Indirect imunofluorescence assay (IFAT) was performed with a Sigma Co. anti-monkey conjugate. Antigen was prepared with $\mathrm{F}$ strain of $T$. cruzi, epimastigotes from eight-days old cultures in LIT liquid medium, were washed three times and finally resuspended in phosphate-buffered saline (PBS); this final suspension, adjusted so that approximately 40 flagellates could be counted per dry high power field, was distributed on the appropriate slides and air-dried at room temperature. No fixative was used. The slides were stored in cans with silica gel at $-20^{\circ} \mathrm{C}$ for no longer than one month. Two blood smears from each animal were Giemsa stained and examined for patent parasitemia.

Biological and molecular characterization Groups of five outbred Swiss mice weighing $18 \mathrm{~g}$ were intraperitoneally inoculated with metacyclic forms that were derived from LIT medium $\left(1 \times 10^{5}\right.$ parasites) of 21 tamarin isolates. The parasitemia was followed every other day in fresh blood smears and counts were performed in a Neubauer chamber. The isoenzymatic eletrophoretic profile analysis was performed according to Momen and Salles (1985). The enzymes that were tested were glucose phosphate isomerase (GPI), (E.C. 5.3.1.9), malic (ME), (E.C.1.1.1.40), isocitrate dehydrogenase (IDH), (E.C. 1.1.1.42), glucose 6 phosphate dehydrogenase, (G6PDH), (E.C.1.1.1.49) and malato dehydrogenase (MDH), (E.C.1.1.1.37). Each electrophoresis included Y (T. cruzi II) and F (T. cruzi I) as reference strains. The KDNA from the flagellates for schizodeme analysis was extracted by phenol-chloroform and alcohol precipitation and digested with EcoR1 as described by Gonçalves et al. (1990).

\section{RESULTS}

Natural infection of tamarins - Sixty one of the 118 tamarins (52\%) sampled demonstrated positive IFAT results. T. cruzi was isolated in the hemocultures of 38 tamarins. All examined groups contained infected animals but the percentage of infection varied significantly (Table I). No animal displayed patent parasitemia. The prevalence of infection was $64.29 \%$ for 56 adults, $36.36 \%$ for 44 juveniles and $0 \%$ for eight tested infants. The prevalence was greater for adults ( 36 positive of 56 tested) than for juveniles (16 positive of 44 tested), (Chi square test: $\chi^{2}=18.79 p<0.001$ ). There was no statistically significant difference as to prevalence between males ( $49.1 \%$ were positive, 57 were tested) and females ( $45.1 \%$ were positive, 51 were tested), (Chi square test: $\chi^{2}=0.4902, p=0.4838$ ).

Our data suggest that $T$. cruzi infection in $L$. rosalia is stable. Recaptured animals displayed positive hemocultures and IFAT for up to 36 months. Transmission of T. cruzi is still occuring in the reserve since three previously uninfected tamarins became serologically and parasitologically positive 
after periods that varied from 8-12 months (tamarins nos 456, 567 and 593) (Table II).

Moreover, the composition of the groups of tamarins remained almost the same during our follow up since only two animals moved to other groups.

T. cruzi isolates derived from infected tamarins were more virulent for Swiss mice than previous observations with sylvatic isolates: 19 isolates induced high patent parasitemia and 11 caused mortality in the experimentally infected mice. Only two tamarin isolates determined subpatent infection in experimentally infected mice (Table III).

No correlation could be established between parasitemia and mortality or between the biological

\section{TABLE I}

Distribution of Trypanosoma cruzi infection in Leontopithecus rosalia according to the distinct tamarins groups at the Reserva Biológica de Poço das Antas: serological and parasitological follow up of 21 groups

\begin{tabular}{lccc}
\hline Glt group & No. of animals/group & No. of examined animals & Positive IFAT/hemocultures \\
\hline PAG & 6 & 6 & $4 / 3$ \\
PI & 5 & 5 & $5 / 4$ \\
2M & 6 & 6 & $5 / 5$ \\
O3 & 4 & 4 & $3 / 3$ \\
BO2 & 3 & 2 & $2 / 1$ \\
S/G & 6 & 4 & $1 / 1$ \\
BO & 11 & 11 & $6 / 3$ \\
FC & 3 & 3 & $3 / 0$ \\
AS & 10 & 9 & $2 / 2$ \\
PP & 5 & 5 & $4 / 2$ \\
AL & 7 & 4 & $1 / 1$ \\
GC & 6 & 6 & $3 / 0$ \\
EUC & 6 & 6 & $3 / 2$ \\
2F & 5 & 5 & $1 / 1$ \\
CM & 5 & 5 & $5 / 5$ \\
GF & 5 & 5 & $2 / 0$ \\
3M & 6 & 6 & $3 / 1$ \\
CA & 7 & 7 & $2 / 2$ \\
CF & 9 & 7 & $4 / 1$ \\
E2/O2 & 4 & 4 & $1 / 1$ \\
FA & 8 & 8 & $1 / 0$ \\
\hline Total & 5 & 118 & $61 / 38$ \\
\hline
\end{tabular}

Glt: golden lion tamarim; IFAT: indirect immunofluorescence assay

TABLE II

Parasitological and serological data of the natural infection of Leontopithecus rosalia with Trypanosoma cruzi. The serological titers were evaluated by an indirect imunofluorescence assay (IFAT)

\begin{tabular}{ccc}
\hline $\begin{array}{c}\text { Animal number of } \\
\text { golden lion tamarin }\end{array}$ & $\begin{array}{c}\text { Capture } \\
\text { IFAT } \\
\text { titer/hemoculture }\end{array}$ & $\begin{array}{c}\text { Recapture time in months } \\
\text { IFAT titer/hemoculture }\end{array}$ \\
\hline 291 & $1: 40 /+$ & $8 / 1: 40 /+$ \\
456 & Neg/- & $11 / 1: 160 /+$ \\
474 & $1: 80 /+$ & $12 / 1: 1280 /-$ \\
481 & $1: 40 /+$ & $8 / 1: 160 /-$ \\
490 & $1: 40 /-$ & $17 / 1: 40 /+$ \\
524 & $1: 320 /+$ & $2 / 1: 640 /-$ \\
567 & Neg/- & $12 / 1: 1280 /+$ \\
583 & $1: 40 /+$ & $11 / 1: 40 /+$ \\
592 & $1: 80 /+$ & $8 / 1: 160 /-$ \\
593 & Neg/- & $8 / 1: 640 /+$ \\
594 & $1: 1280 /+$ & $8 / 1: 160 /+$ \\
651 & $1: 20 /-$ & $17 / 1: 40 /-$ \\
652 & $1: 160 /+$ & $2 / 1: 320 /-$ \\
\hline
\end{tabular}




\section{TABLE III}

Follow up of the experimentally infected Swiss mice by Trypanosoma cruzi isolates obtained from naturally infected Leontopithecus rosalia. Mice were inoculated introperitoneally with $10^{5}$ matacyclic forms derived from axenic culture media

\begin{tabular}{cccc}
\hline $\begin{array}{c}\text { T. cruzi isolates on } \\
\text { animals number }\end{array}$ & $\begin{array}{c}\text { Prepatent period } \\
\text { (days) }\end{array}$ & $\begin{array}{c}\text { Peak of parasitemia } \\
\text { (day-parasites/ml) }\end{array}$ & $\begin{array}{c}\text { Mortality/ } \\
\text { inoculated mice }\end{array}$ \\
\hline 583 & 4 & $19-88 \times 10^{4}$ & $4 / 5$ \\
636 & 12 & $19-92 \times 10^{4}$ & $4 / 5$ \\
656 & 9 & $13-9.5 \times 10^{4}$ & $4 / 5$ \\
474 & 7 & $14-15 \times 10^{4}$ & $4 / 5$ \\
659 & 12 & $21-45 \times 10^{4}$ & $3 / 5$ \\
567 & 7 & $23-29 \times 10^{4}$ & $3 / 5$ \\
672 & 12 & $23-58 \times 10^{4}$ & $2 / 5$ \\
544 & 17 & $33-11 \times 10^{4}$ & $2 / 5$ \\
543 & 11 & $26-0.8 \times 10^{4}$ & $1 / 5$ \\
689 & 7 & $21-33,8 \times 10^{4}$ & $1 / 5$ \\
456 & 12 & $19-33.5 \times 10^{4}$ & $1 / 5$ \\
594 & 16 & $16-0.8 \times 10^{4}$ & $0 / 5$ \\
684 & 7 & $28-11 \times 10^{4}$ & $0 / 5$ \\
661 & 19 & $21-3 \times 10^{4}$ & $0 / 5$ \\
495 & 7 & $33-0.8 \times 10^{4}$ & $0 / 5$ \\
593 & 14 & $26-10.7 \times 10^{4}$ & $0 / 5$ \\
635 & 26 & $26-1.2 \times 10^{4}$ & $0 / 5$ \\
652 & 19 & $31-27.7 \times 10^{4}$ & $0 / 5$ \\
524 & 11 & $26-1.6 \times 10^{4}$ & $0 / 5$ \\
90 & - & - & $0 / 5$ \\
439 & - & - & $0 / 5$ \\
\hline
\end{tabular}

markers with the schizodeme that was the same for all isolates.

Schizodeme analysis showed no important heterogenity among golden lion tamarin isolates (Fig. 1). All of the 15 isolates that have already been characterized were in the Z2 zymodeme according to Miles et al. (1986) when tested for glucose phosphate isomerase (GPI), (E.C. 5.3.1.9), malic (ME), (E.C.1.1.1.40), isocitrate dehydrogenase (IDH), (E.C. 1.1.1.42), glucose 6 phosphate dehydrogenase, (G6PDH), (E.C.1.1.1.49) and malato dehydrogenase (MDH), (E.C.1.1.1.37) (Fig. 2 A-E). Reisolated parasites derived from tamarins recaptured $(n=3)$ months after the first positive hemoculture remained in the same zymodeme.

\section{DISCUSSION}

Golden lion tamarins are small, arboreal primates that feed largely on fruit and insects (Dietz et al. 1997). They live in relatively stable social groups with an average of 5.4 individuals each (Baker et al. 1993, Dietz \& Baker 1993), occupy territories of about 42 ha (Dietz et al. 1994) and sleep in tree holes at night (Coimbra-Filho 1977). The geographic distribution of golden lion tamarins once extended from the State of Espírito Santo to the State of São Paulo, Brazil. However, most of the original forest in this region has been converted to cattle pasture and agricultural fields. Golden lion tamarins are now restricted to a few forest fragments in the State of Rio de Janeiro, and 476 individuals live in 134 zoos worldwide. The species is considered critically endangered of extinction in the wild.

T. cruzi infection has been documented among many New World primates, but little is known about transmission cycles involving free-ranging nonhuman primates. To our knowledge, no such study has been conducted at the population level. Lourenço-de-Oliveira (1990), was the first to report T. cruzi infection in golden lion tamarins at the Reserva Biológica de Poço das Antas. In 1989 he observed five positive blood smears out of 17 examined. The author, however, did not perform any characterization of the parasite. We were unable to detect patent parasitemia in any of the 61 tamarins with positive IFAT results. The differing results between these two studies might mean that the onset of this enzootic disease among the tamarins started in 1989, when animals in the acute phase would likely have been numerous.

Vertical transmission of $T$. cruzi among golden lion tamarins is unlikely since none of the examined infants tested positive. Congenital transmission 
of $T$. cruzi is rare among humans and other mammalian orders including Marsupialia (Jansen et al. 1994). Infection of free-ranging tamarins with T. cruzi probably occurs by contamination with the feces of infected triatomine bugs, since these primates do not include hemipterans in their diet

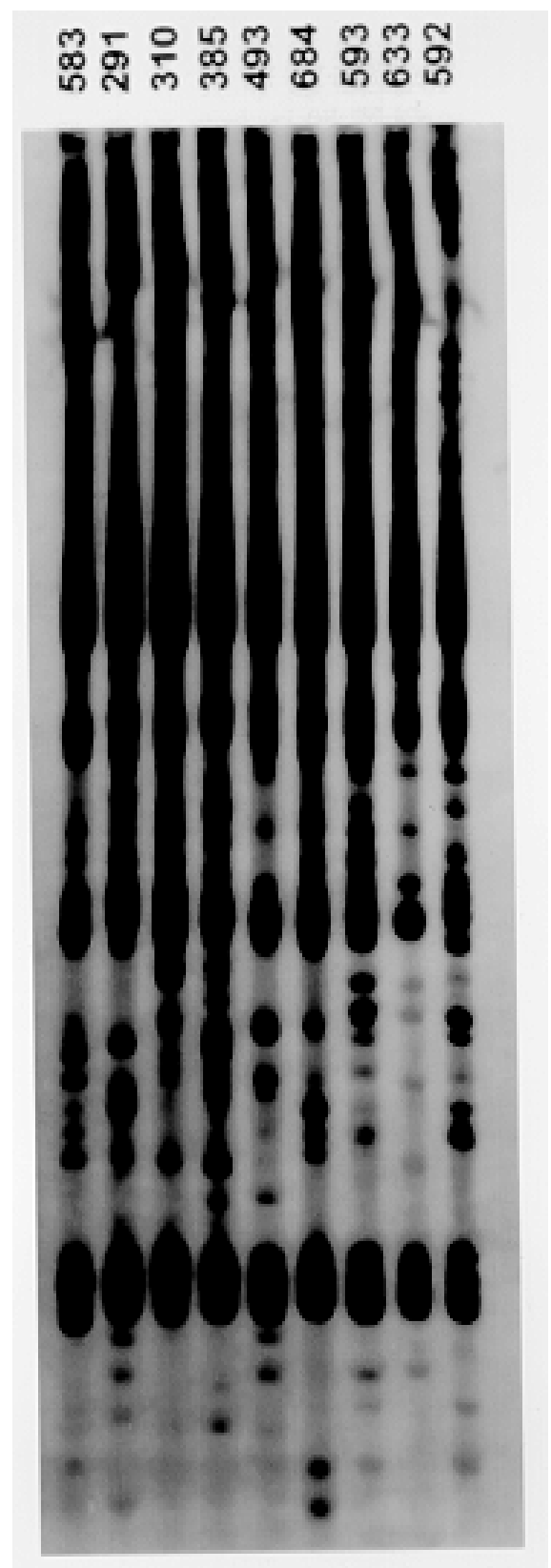

Fig. 1: schyzodeme analysis of Trypanosoma cruzi isolates from golden lion tamarins, (Leontopithecus rosalia), using the restriction enzyme EcoR1. Each number signifies one isolate for each golden lion tamarin especimen. Lanes 1 to 9 correspond to isolates of animals 583, 291, 310, 385, 493, 584, 593, 633 and 592.
(Coimbra-Filho 1972, Coimbra-Filho \& Mittermeier 1981). Furthermore, tamarin's habitual use of a few tree holes as sleeping sites makes it likely that infection occurs at night at these dens. The fact that the rate of infection was greatest among older animals but was not sex biased adds support to the hypothesis that tamarins are infected over time by exposure to infected insects.

At least one tamarin tested positive in each of the 21 studied groups, which suggests that $T$. cruzi infection is ubiquitous in the reserve's population. The significant variation between each group of tamarins may be due to the peculiarities of each group's behaviour. Indeed, those tamarin groups with high percentages of infected animals used the same sleeping sites.

The transmission cycle of $T$. cruzi is still occurring among this population of tamarins as could be demonstrated by the three animals that tested negative (IFAT and hemoculture) in a first examination and yielded positive results some months later.

Natural infection of golden lion tamarin is stable and longlasting as could be observed in the recaptured animals that remained infected after periods up to 36 months. Moreover, the subpopulations of the parasite were apparently not selected by the host since the enzymic profile of three reisolates remained in the same zymodeme.

Serological titers as high as 1:1280 were observed, although the average was 1:160. The serological titer of 1:40 that was observed for one animal indicates a recently acquired infection since its hemoculture was also positive. The 1:20 serological titer that was observed for one animal whose hemoculture was negative is probably due to a cross-reaction with monogenetic trypanosomatids since tamarins feed on many taxa of insects.

Positive hemoculture were observed for $62.3 \%$ of the tamarins that yielded positive serological results. Hemoculture is not a sensitive parasitological method and contamination in field conditions may explain this difference.

In contrast with findings by Sullivan et al. (1993), for squirrel monkeys (Saimiri sciureus), golden lion tamarins displayed a significant humoral imune response to $T$. cruzi in our study.

A puzzling aspect of our results is that $T$. cruzi isolates from the free-ranging tamarins displayed a Z2 profile that Miles et al. (1977) and Miles and Cibulskis (1986) found to be related to the domiciliar transmission cycle. Moreover, the 26 mini-exon typed tamarins isolates, were in lineage 1 (T. cruzi II), (Fernandes et al. 1998). Previous studies with molecular markers (mini-exon and $24 \mathrm{~S}$ rRNA) showed a preferential association of lineage 1 ( $T$. 

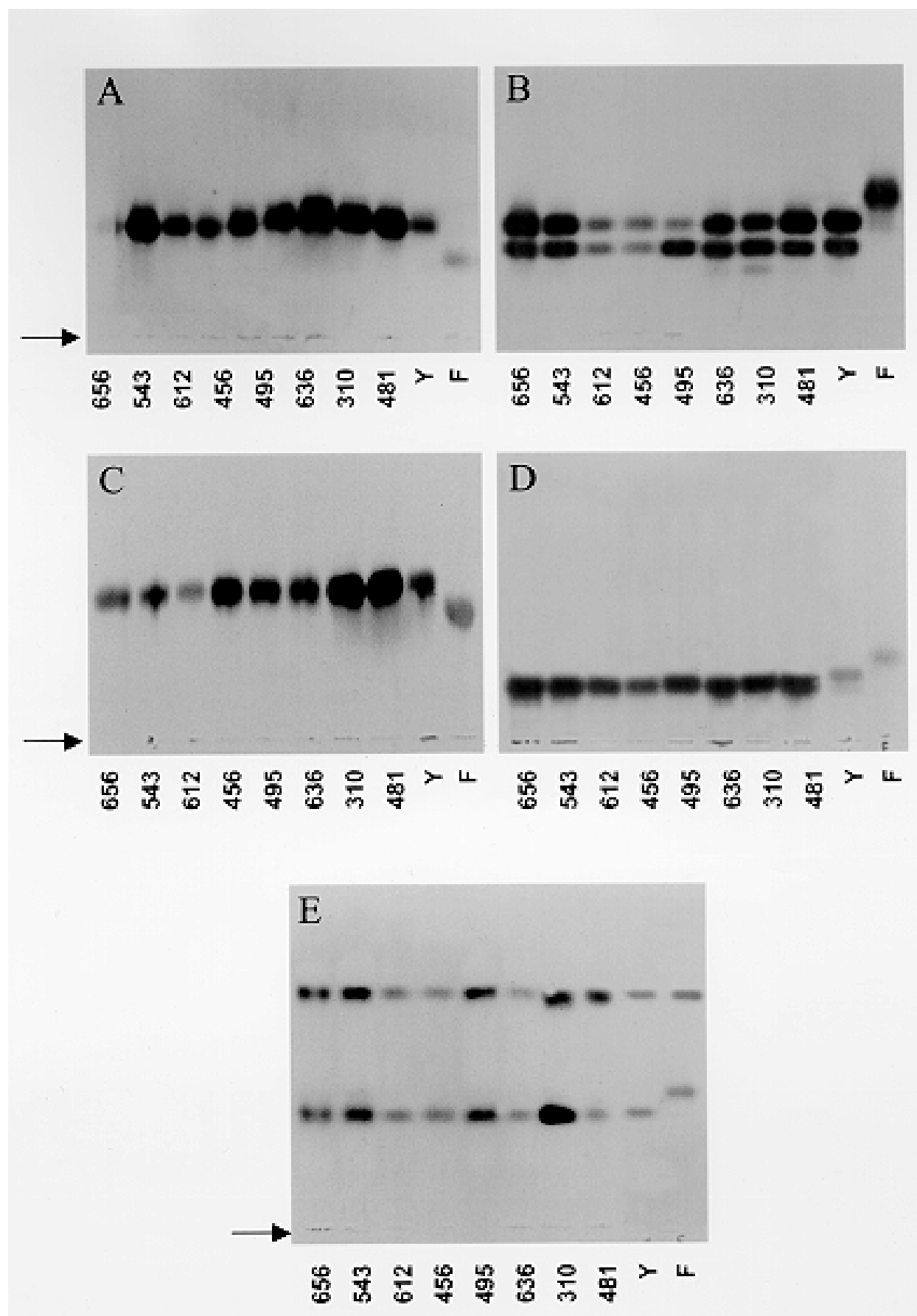

Fig. 2: isoenzyme profile plate comparing enzyme mobilities of culture forms of Trypanosoma cruzi isolates obtained from Leontopithecus rosalia. Agarose gels stained for activity of the following enzymes: glucose phosphate isomerase, isocitrate dehydrogenase, glucose 6 phosphate dehydrogenase, malato dehydrogenase and malic. The arrow indicates the origin. Each number correspond to one isolate and lanes 9 and 10 correspond to the reference strains $\mathrm{Y}$ and $\mathrm{F}$, respectively, zymodemes 2 and 1 . 
cruzi II) with the domestic transmission cycle and of lineage 2 (T. cruzi I) with the sylvatic one (Souto et al. 1996, Zingales et al. 1998, Fernandes et al. 1998).

Biological characterization showed that the tamarin isolates are significantly more virulent for Swiss mice than those from other sylvatic mammals in the Reserva Biológica de Poço das Antas (Lisboa et al. 1996). However, we do not yet know the consequences of the natural infection with $T$. cruzi for $L$. rosalia. It is known that experimentally infected primates display an acute disease that is similar to Chagas disease although they do not mimic the human chronic phase of the disease (Bonecini-Almeida et al. 1990). The impact of the infection in other animals in the Reserve or in humans is also unpredictable.

Reintroduction of captive-born tamarins and translocation of wild-born tamarins has been deemed a necessity in order to keep the species from becoming extinct in the wild (Kleiman et al. 1990). Prior to reintroduction, captive-born tamarins are quaranteened and tested for hepatitis, herpes and toxoplasmosis, but not for trypanosomiasis or leishmaniasis. Our results suggest that the latter tests should be conducted as well, especially in the case of callitrichids that is brought by nature into the captive population.

Our results with regard to T. cruzi subpopulation are surprising when associated to the domestic transmission cycle and they deserve further study. Our findings suggest the need for additional research on the relationship between $T$. cruzi and free-ranging New-World Primates. Among the questions that still need an answer are, for instance, the following: is T. cruzi infection in the golden lion tamarins at the Reserva Biológica de Poço das Antas enzootic or epizootic? How long will it be maintained in the population? What are the effects of the infection on the survival and on the reproductive success of individual tamarins in naive and infected populations? What effects can be expected due to concomitant infections? What are the consequences of the increase of host density? What are the consequences of the circulation of $\mathrm{Z} 2 / T$. cruzi II subpopulation for the surrounding human population?

\section{ACKNOWLEDGEMENTS}

To the Associação Mico Leão Dourado, the National Science Foundation (Grants BNS-8616480 and 89419399 to Dietz, and BNS-9008161 to J Dietz and A Baker), International Environmental Studies Program of the Smithsonian Institution, WWF-US, National Geographic Society, Friends of the National Zoo. To Alcidinéia Ivo for technical support and Rodrigo Mexas for the photograph plates.

\section{REFERENCES}

Aben-Athar J 1922. Primeiro ano de funcionamento do Instituto Hygiene de Belém. In AC Souza Araújo, A Prophylaxia Rural no Estado do Pará, Liv. Gillet, Pará, 190 pp.

Almeida EA, Navarro MR, Guariento ME, Carvalhal SS 1992. Infecção experimental de macacos Cebus apella sp. pelo Trypanosoma cruzi. Avaliação clínica, eletrocardiográfica. Rev Soc Bras Med Trop 25: 712.

Ayala FM 1961. Hallazgo del T. cruzi, Chagas, 1909 en el mono Saimiri boliviensis de la Amazonia peruana. Rev Bras Malariol Doenças Trop 13: 99-105.

Ayala SC, D'Alessandro A, MacKenzie R, Angel D 1973. Hemoparasite infections in 830 wild animals from the eastern Llanos of Colombia. J Parasitol 59: 5259.

Baker AJ, Dietz JM, Kleiman DG 1993. Behavioural evidence for monopoligation of paternity in multimale groups of golden lion tamarins. Anim Behav 46: 1091-1103.

Brener Z 1973. Biology of Trypanosoma cruzi. Annu Rev Microbiol 27: 240-247.

Bonecini-Almeida MG, Galvão-Castro B, Pessoa MHR, Pirmez C, Laranja F 1990. Experimental Chagas disease in Rhesus monkeys. 1. Clinical parasitological, hematological and anatomo-pathological studies in the acute and indeterminate phase of the disease. Mem Inst Oswaldo Cruz 85: 163-171.

Chagas C 1924. Infeccion naturelle chez des singes du Pará (Chrysothrix scuireus) par Trypanosoma cruzi. C R Séances Soc Biol Fil 90: 873-876.

Coimbra-Filho AF 1972. Aspectos inéditos do comportamento de sagüis do gênero Callithrix (Callithricidae - Primates). Rev Bras Biol 32: 505512.

Coimbra-Filho AF 1977. Natural shelters of Leontopithecus rosalia and some ecological implications (Callithricidae-Primates). In DG Kleiman, The Biology and Conservation of the Callitrichidae, Smithsonian Institution, Washingnton, p. 79-89.

Coimbra-Filho AF, Mittermeier RA 1981. Ecology and behavior of neotropical primates. Aspectos inéditos do comportamento de sagüis do gênero Callithrix (Callithricidae-Primates). Rev Bras Biol 32: 505-512.

Deane LM 1962. Infecção natural do sagüi Callithrix jacchus por tripanosoma do tipo cruzi. Rev Inst Med Trop São Paulo 4: 225-229.

Deane LM, Damasceno RR 1961. Tripanosomídeos de mamíferos da região amazônica. II Tripanosomas de macacos da zona do Salgado, Estado do Pará. Rev Inst Med Trop São Paulo 3: 61-70.

Deane LM, Batista D, Ferreiro-Neto FA, Souza H 1970. Tripanosomídeos de mamíferos da região amazônica. V Trypanosoma lambrechti Marinkelle, 1968 em macacos do Estado do Amazonas, Brasil. Res Inst Med Trop São Paulo 12: 1-7.

Deane MP, Jansen AM, Lenzi HL 1984. Trypanosoma cruzi: vertebrate and invertebrate cycles in the same mammal host the opossum Didelphis marsupialis. 
Mem Inst Oswaldo Cruz 79: 513-515.

Dietz JM, Baker AJ 1993. Polygyny and female reproductive success in golden lion tamarins (Leontopithecus rosalia). Anim Behav 46: 1067-1078.

Dietz JM, Baker AJ, Miglioretti D 1994. Seasonal variation in reproduction, juvenile growth and adult body mass in golden lion tamarins (Leontopithecus rosalia). Am J Primatol 34: 115-132.

Dietz JM, Peres CA, Pinder L 1997. Foraging ecology and use of space in wild golden lion tamarins (Leontopithecus rosalia). Am J Primatol 41: 289305.

Fernandes O, Mangia RH, Lisboa CV, Pinho AP, Morel CM, Zingales B, Campbell DA, Jansen AM 1998. The complexity of the sylvatic cycle of Trypanosoma cruzi in Rio de Janeiro state (Brazil) revealed by the non-transcribed spacer of the mini-exon gene. Parasitology 118: 161-166.

Gonçalves AM, Nédia SNN, Morel CM 1990. Trypanosomatid characterization by schizodeme analysis. In CM Morel, Gene and Antigens of Parasites, Editora Fiocruz, Brasil, p. 95-109.

Jansen AM, Madeira FB, Deane MP 1994. Trypanosoma cruzi infection in the opossum Didelphis marsupialis: absense of neonatal transmission and protection by maternal antibodies in experimental infection. Mem Inst Oswaldo Cruz 89: 41-45.

Kierulff MCM, Oliveira PP 1994. Habitat preservation and the translocation of threatened groups of golden lion tamarins, L. rosalia. Neotrop Primates 2: 1518.

Kleiman DG, Beck BB, Baker AJ, Ballou JD, Dietz LA, Dietz JM 1990. The Conservation program for the golden lion tamarin. Endangered species. UPDATE 8: $82-85$.

Lisboa CV, Mangia RH, Menezes-Trajano V, Nehme NS, Morel CM, Jansen AM 1996. Ecological aspects of the circulation of Trypanosoma cruzi in the sylvatic environment. Mem Inst Oswaldo Cruz 91: 279.

Lourenço-de-Oliveira R 1990. Natural infection of golden lion tamarin, Leontopithecus rosalia with Trypanosoma cruzi in the State of Rio de Janeiro, Brasil. Mem Inst Oswaldo Cruz 85: 15.

Marinkelle CJ 1966. Observations on human, monkey and bat trypanosomes and their vectors in Colom- bia. Trans $R$ Soc Trop Med Hyg 60: 1 .

Marinkelle CJ 1982. The prevalence of Trypanosoma (Schizotrypanum) cruzi infection in Colombian monkeys and marmosets. Ann Trop Med Parasitol 76: 121-124.

Marsen PD, Seah SKK, Mott KE, Prata A, Platt H 1970. Immunoglobulins in Chagas' disease. Ann Trop Med Parasitol 73: 157-161.

Miles MA 1983. The epidemiology of South American trypanosomiasis, biochemical and immunological approaches and their relevance to control. Trans $R$ Soc Trop Med Hyg 77: 5-23.

Miles MA, Cibulskis RE 1986. The heterogeneity of Trypanosoma cruzi. Parasitol Today 2: 94-97.

Miles MA, Toyé PJ, Oswaldo SC, Godfrey DG 1977. The identification by isoenzyme patterns of two distinct strain groups of Trypanosoma cruzi, circulating independently in a rural area of Brasil. Trans $R$ Soc Trop Med Hyg 71: 217-225

Momen H, Salles CA 1985. Enzyme markers for Vibrio cholerae: identification of classical, El Tor and environmental strains. Trans $R$ Soc Trop Med Hyg 79: 773-776.

Rosner JM, Schinini A, Rovira T, Arlas A, Velásquez G, Idalla-Monzón M, Maldonado M, Ferro EA, Galeano R 1988. Acute Chagas' disease in non-human primates. 1. Chronology of clinical events, clinical chemistry, ECG, radiology, parasitemia and immunological parameters in the Cebus apella monkey. Trop Med Parasitol 39: 51-55.

Souto R, Fernandes O, Macedo AM, Campbell DA, Zingales B 1996. DNA markers define two major phylogenetic lineages of Trypanosoma cruzi. Mol Biochem Parasitol 83: 141-152.

Sullivan JJ, Steurer F, Benavides G, Tarleton RR, Eberhard ML, Landry S 1993. Trypanosomes and microfilariae in feral owl and squirrel monkeys maintained in research colonies. Am J Trop Med Hyg, 49: 254-259.

Zingales B, Souto RP, Mangia RH, Lisboa CV, Campbell D, Coura JR, Jansen AM, Fernandes O 1998. Molecular epidemiology of American trypanosomiasis in Brazil based on dimorphisms of rRNA and mini-exon gene sequences. Int J Parasitol 28: 105-112. 